\title{
COMBINED OFF-PUMP CORONARY REVASCULARIZATION AND LUNG RESECTION
}

\author{
Cengiz Köksal, Sabit Sarıkaya, Mustafa Zengin, Ali Atasalihi
}

Sureyyapasa SSK Thoracic and Cardiovascular Disease Hospital, Maltepe-Istanbul, Turkey: Cardiovascular Surgery Clinic

Summary: Concomittant severe coronary artery disease and lung malignancies occur rarely. Combined conventional coronary artery bypass grafting (CABG) with the use of cardiopulmonary bypass (CPB) with lung resection posses several perioperative and postoperative problems related to extracorporeal circulation and heparinization. The avoidance of CPB may be advantageous by decreasing blood loss, pulmonary complications and hospital stay. Further, exposure to the immunosuppresive and inflammatory effects of CPB may have deleterious impact on tumor growth and dissemination. Off-pump CABG makes the combined procedure safer as it abolishes the complications of CPB. We report two patients with the diagnosis of severe coronary artery disease and lung malignancies, underwent off-pump CABG and lung resections in the same surgical setting.

Key words: Coronary artery bypass; Lung cancer; Cardiopulmonary bypass

\section{Introduction}

Concomitant coronary artery disease requiring coronary surgery and lung cancer are uncommon with an incidence of $0.3-0.4 \%$ of patients undergoing coronary artery revascularization (4). When present, they pose a therapeutic dilemma whether to choose a combined or staged surgical procedure.

One staged combined procedure avoids the need for a second major thoracic procedure, may shorten hospital stay as it reduces economic burden and may improve early surgical results and late follow-up (6). Though simultaneous coronary artery revascularization with $\mathrm{CPB}$ and lung resection has given satisfactory results, controversy exists about using extracorporeal circulation in this combined procedure (2). Nowadays, there is growing concern about off-pump coronary bypass in order to avoid disadvantages of $\mathrm{CPB}$ and heparinization.

We present here two patients underwent simultaneous off-pump CABG and lung resections either through a midline sternotomy or using two separate incisions for each surgical procedure.

\section{Case 1}

A 67-year-old man was referred to thoracic surgery clinic with a diagnosis of squamous cell cancer of the left upper lobe. He had a history of angina pectoris, stable on medical treatment. He had an inferior myocardial infarct in 1996 and medical history included hypertension. He was a heavy smoker, one pack a day for 36 years. The CT scan confirmed a left lobe peribronchial mass of $3 \mathrm{~cm}$. in diameter and accompanying left lobe atelectesia (Fig 1). Bronchoscopy showed complete obstruction of the left lower lobe bronchus after linguler lobe division. Preoperative staging was T2N1M0 and in the absence of systemic metastases, complete resection was decided. His exercise test was pathological and coronary angiography demonstrated $80 \%$ left anterior descending artery and $70 \%$ right coronary artery stenosis.

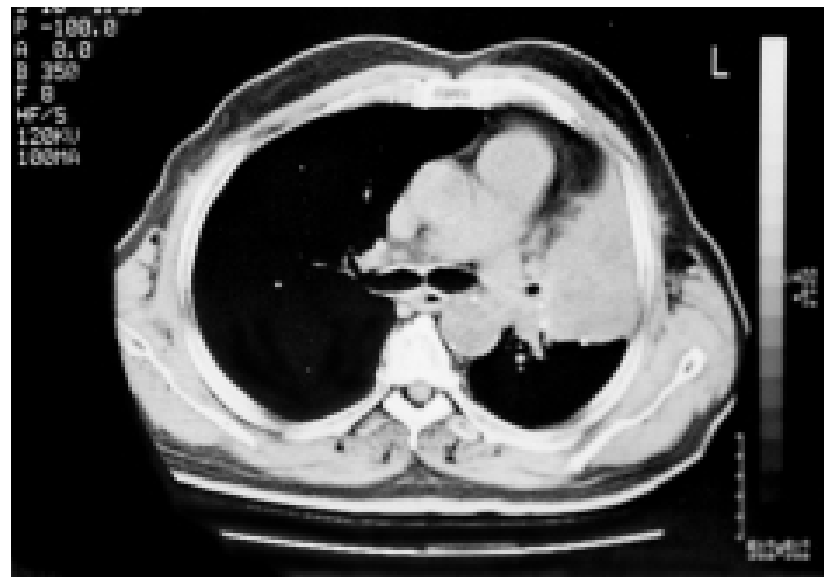

Fig. 1: Left upper lobe tumor with atelectesia. 
At operation, a double lumen endotracheal tube was positioned and standard midline sternotomy was performed. Using Cohn cardiac stabilizer (Genzyme Corporation), the left internal mammary artery was anastamosed to the left anterior artery and a segment of saphenous vein was anastamosed to the right posterior descending artery on the beating heart. After coronary revascularization, the patient was positioned for posterolateral thoracotomy. Left pneumonectomy was done with mediastinal lymph node dissec tion. Bronchus closure was performed by stapling. Throughout the procedure the patient's hemodynamics were stable and his saturations were satisfactory. The patient was extubated the next morning, maintaining good arterial blood gases and stable hemodynamics after extubation. The overall postoperative course was uneventful and the patient was discharged on $10^{\text {th }}$ postoperative day. 8 months after surgery, the patient is asymptomatic.

\section{Case 2}

A 72-years-old man was referred to thoracic surgery clinic by the diagnosis of lung mass of the right upper lobe. His symptoms were hemoptysis and dispne. Medical history was unremarkable. He was a heavy smoker 1 and $1 / 2$ packs a day for 40 years until one month of surgery. Chest CT scan revealed a mass in the right upper lobe. He underwent bronchoscopy, which was normal, however bronchial washing from the right upper lobe revealed atypical squamous cells. Preoperative staging was T2N0M0. There were ischemic changes on ECG and he underwent cardiopulmonary exercise test. The test was discontinued due to chest pain. Coronary angiography demonstrated $70 \%$ proximal left anterior descending coronary artery stenosis. The complexity of the lesion was considered to be a contraindicaton for PTCA.

At operation a double lumen endotracheal tube was positioned and a midline sternotomy was performed. Using the same heart stabilizer a segment of saphenous vein was anastamosed to left anterior descending artery on the beating heart. Through the same surgical access, a right upper lobectomy was performed. Bronchus closure was performed by stapling and meticulous mediastinal and hiler lymph node dissection was done. Postoperative course was uneventful and he was extubated at the $8^{\text {th }}$ hour. After 10 days he was discharged from the hospital. One year after surgery he is well and asymptomatic.

\section{Discussion}

A combined surgical procedure is ideal for the treatment of severe coronary artery disease requiring coronary revascularization and lung malignancies. Moreover, coronary surgery should be performed prior to lung resection, in order to minimize the risk of bleeding, pulmonary complications and the risks related to increased myocardial oxy- gen consumption during and after lung resections (7). Although there are reports concerning the safe use of CPB in combined procedure, the avoidance of CPB may be beneficial by reducing the associated morbidity.

Cardiopulmonary bypass has been shown to produce several systemic side effects including inflammatory stimulation, immunesuppression and those related to heparinization, which further may cause bleeding $(3,6)$. The impact of $\mathrm{CPB}$ on long-term survival is of concern in patients with malignant disease. Exposure of the immunosuppressive and inflammatory effects of CPB may provide a window for malignant growth and dissemination (4) In their study by Akchurin and co-workers, tumor cells were found on the internal surface of heart-lung machine arterial filters, which makes systemic seeding of malignant cells evident while resecting neoplasms during CPB (1). Pulmonary dysfunction sustained during CPB is another matter of concern. In patients with established lung disease, lung injury caused by CPB may prolong hospital stay as it increases economic burden. Moreover, the edema of the peribronchial tissue associated with the use of CPB may adversely affect healing of the bronchial closure (5). All these adverse effects of CPB may be avoided by off-pump coronary revascularization and clinical results may be improved.

Combined CABG and lung resection surgery can be performed through median sternotomy whenever feasible, however, left pneumonectomy is technically difficult through median sternotomy as the dissection tends to be obscured by the heart. In the first case a left posterolateral thoracotomy was performed shortly after off-pump coronary surgery.

\section{Conclusion}

We believe that off-pump coronary surgery concomitant with lung resections makes the combined procedure safer and ideal for patients suffering severe coronary artery disease coexisting with lung malignancies. Combined procedure may be performed through median sternotomy when feasible or both median sternotomy and posterolateral thoracotomy.

\section{References}

1. Akchurin RS, Davidov MI, Partigulov SA et al. Cardiopulmonary bypass and cellsaver technique in combined oncologic and cardiovascular surgery. Aktif Organ 1997Jul;21(7):763-5.

2. Brutel de la Riviere A, Knaepen P, van Swietel H, et al. Concomitant open heart surgery and pulmonary resection for lung cancer. Eur J Cardiothorac Surg 1995;9:310-4.

3. Butler J, Rooker GM, Westaby S. Inflammatory response to cardiopulmonary bypass. Ann Thorac Surg 1993;55:552-9.

4. Danton MH, Anikin VA, Mcmanus KG, Mc Guigan JA, Campalani G. Simultaneous cardiac surgery with pulmonary resection: presentation of series and review of literature. Eur J Cardiothorac Surg 1998; 13: 667-672.

5. Mariani MA, Boven WJ, Duurkens VAM, Ernst SM, van Swietel HA. Combined off-pump coronary surgery and right lung resections through midline sternotomy. Ann Thorac Surg 2001;71:1343-4.

6. Rao V, Todd TR, Weisel RD et al. Results of combined pulmonary resection and cardiac operation. Ann Thorac Surg 1996;62:342-7. 
7. Ulincy KS Jr, Schmelzer V, Flege JB Jr et al. Concomitant cardiac and pulmonary operation: the role of cardiopulmonary bypass. Ann Thorac Surg 1992;54:289-95.

Submitted February 2002.

Accepted May 2002.

Cengiz Köksal, M.D.,

P.O.Box 26, Cerrahpasa,

34301-Istanbul, Turkey.

e-mail: cengizkoksal@hotmail.com 